\title{
Research on Target Detection Probability Model of Penetration Plane During the Final Stage
}

\author{
Daowei Liu ${ }^{1, a}$, Jie Xiong ${ }^{2, b}$, Yu Wang ${ }^{3, c}$ and Jingping Huang ${ }^{4, d}$ \\ 1,2,3,4 Luoyang Electronic Equipment Test Center of China, Luoyang, China \\ a66359150@qq.com, b1650605@qq.com, '942908@qq.com, '9429208@qq.com
}

\begin{abstract}
Keywords: Ground-to-air radar jamming; Self-protection jamming; Suppression region; Target Detection Probability
\end{abstract}

\begin{abstract}
Based on comprehensive consideration of factors such as the enemy's ground-to-air radar jamming system, air defense missile system and the side direction deviating distance target of Penetration Plane, effective range of airborne weapon, target detection probability model of penetration plane during the final stage were established, finally, through the simulation, the main factors of model were analyzed and verified.
\end{abstract}

\section{Introduction}

The implementation of the penetration aircraft to ground attack, the enemy will be joint air defense system information and fire one of the threats, in order to ensure the successful completion of the penetration aircraft scheduled task, on the one hand, to reduce the probability of hitting the enemy is attacking aircraft air defense missile weapon system; on the other hand, should be in the penetration aircraft airborne radar jamming, complete search and identify targets, and ensure enough time to implement missile attacking [1] on target.

The aircraft penetration probability of target detection is the penetration aircraft within the effective range of airborne weapons, can detect targets on the ground and is not the probability of destroying enemy air defense missile weapon system, the existing literature on the attack effectiveness in attacking aircraft has made some research achievements, such as the literature [2-3] established under the conditions of interference search radar target effectiveness model [4-6] under the condition of no interference; the penetration of air to ground strike related effectiveness model was established in [7-8]; electronic jamming to air entering the target and first attack probability model. But the literature, without considering the enemy ground to air radar jamming system, air defense missile weapon system and penetration into the target plane when the lateral deviation effect of target distance and the effective range of airborne weapon target discovery probability. In this paper, we establish the probability model of the aircraft to detect the target in the ground attack stage, and analyze the influence of the above factors on the probability of penetration of the aircraft.

\section{Influencing Factors Analysis}

The Calculation of the Effective Suppression Area of Ground Target for Ground to Air Radar Jamming Equipment. The ground plane, ground to air radar jamming equipment and air defense missile weapon system guidance radar are connected as the $\mathrm{X}$ axis to establish the plane coordinate system, as shown in fig. 1 . 


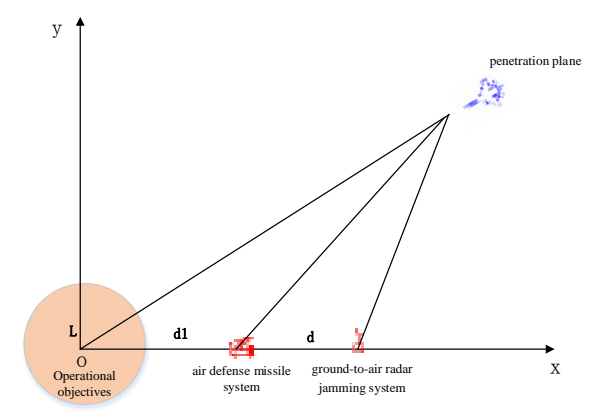

Figure 1. Finite Ground projection of each combat entity

Ground to air radar jamming equipment position (D, 0), air defense missile weapon system guidance radar position $(\mathrm{d}+\mathrm{d} 1,0)$, target equivalent radius is $\mathrm{L}$, and the radar cross section is $\sigma_{0}$, when the airborne radar antenna beam pointing to the ground target edge, the ratio of $P_{r}$ and $P_{r j}$ is Eq. 1 [9]. ${ }_{t}(\varphi)$ for airborne radar antenna in ground to air radar jamming equipment interference in the direction of the gain, calculated by Eq. 2.When $\frac{P_{r j}}{P_{r}}=\mathrm{Kj}$, we can find the relationship Dt and $\alpha$ in Eq. 3.

$$
\begin{aligned}
& \frac{P_{r j}}{P_{r}}=\frac{P_{j} G_{j}}{P_{t} G_{t}} \cdot \frac{4 \pi \gamma_{j}}{\sigma_{0}} \cdot \frac{R_{t}^{4}}{R_{j}^{2}} \cdot \frac{G_{t}(\varphi)}{G_{t}} \cdot \frac{\Delta f_{r}}{\Delta f_{j}} \\
& G_{t}(\varphi)= \begin{cases}G_{t} & 0 \leq \varphi \leq \frac{\theta_{0.5}}{2} \\
K\left(\frac{\theta_{0.5}}{\theta}\right)^{2} G_{t} & \frac{\theta_{0.5}}{2} \leq \varphi \leq 90^{\circ}\end{cases} \\
& \frac{\left(D_{t}^{2}+H^{2}\right)^{2}}{D_{t}^{2}+H^{2}+d^{2}-2 D_{t} d \cos \alpha}=\frac{P_{t} G_{t}}{P_{j} G_{j}} \cdot \frac{\sigma_{0} K_{j}}{4 \pi \gamma_{j}} \cdot \frac{1}{K \theta_{0.5}^{2}} \cdot \frac{\Delta f_{j}}{\Delta f_{r}} \cdot\left[\arcsin \frac{L}{D_{t}}+\arctan \frac{d \sin \alpha}{D_{t}-d \cos \alpha}\right]^{2}
\end{aligned}
$$

Assuming that the penetration of the aircraft into the target along the $\mathrm{X}$ axis, according to the formula to achieve the ground target as the center, with Dt and $\alpha$ as the variable of the effective interference area graphics, as shown in Fig. 2.

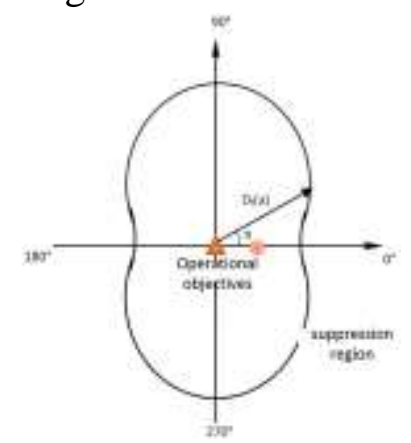

Figure 2. Finite The effective suppression area of ground to Air Radar Jamming 
The Calculation of the Effective Suppression Area of Air Defense Radar. When the aircraft is self defense, $R_{t}=R_{j}, \varphi=0, G_{t}(\varphi)=G_{t}, \mathrm{R} 0$ is Eq. 4,D0 is Eq. 5.At this point, the air defense missile system radar coverage area is the radius of D0.

$$
\begin{gathered}
R_{0}=\left(\frac{K_{j} P_{t} G_{t} \sigma_{0} \Delta f_{j}}{4 \pi \gamma_{j} P_{j} G_{j} \Delta f_{r}}\right)^{\frac{1}{2}} \\
D_{0}=\sqrt{R_{0}^{2}-H^{2}}
\end{gathered}
$$

Probability Calculation of Ground Target Falling into Penetration Radar. The projection of the plane's distance from the target to the horizontal plane is Eq.6.[10], and the probability density function of the lateral deviation from the target is Eq.7. The projection of the airborne radar to the ground target is shown in fig 3.

$$
\Delta Z=\Delta \varepsilon \cdot R_{L}
$$

(6)

$$
f(\Delta z)=\frac{1}{\sqrt{2 \pi} \sigma_{\varepsilon} R_{L}} \cdot e^{-\frac{\Delta z^{2}}{2\left(\sigma_{\varepsilon} R_{L}\right)^{2}}}
$$

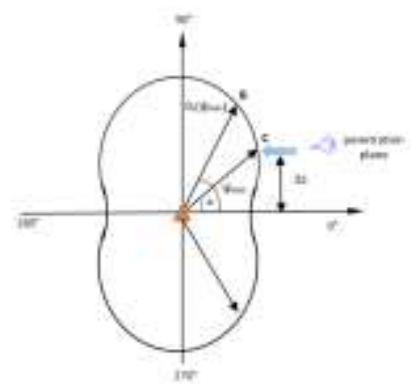

Figure 3. Finite Penetration aircraft search ground target projection

In the penetration aircraft airborne radar detect probability region affected by airborne radar search angle target on the ground, the airborne radar is $\pm \varphi_{\max }$ at the level of the maximum search angle, such as the figure $\mathrm{B}, \mathrm{C}$ for the actual position of the penetration aircraft, to make the penetration aircraft can detect ground targets should meet $\alpha<\varphi_{\max }$, see Eq. 8.Without considering the minimum launch range of airborne weapon Rmin and the threat of enemy air defense missile weapon system, the probability of the target falling into the effective detection area of the airborne radar of the penetration aircraft is shown in Eq. 9. 
$\Delta z<D_{t}\left(\varphi_{\max }\right) \bullet \sin \varphi_{\max }$

(8)

$P_{L}=2 \int_{0}^{D_{t}\left(\varphi_{\max }\right) \cdot \sin \varphi_{\max }} f(\Delta z) d \Delta Z=2 \int_{0}^{D_{t}\left(\varphi_{\max }\right) \cdot \sin \varphi_{\max }} \frac{1}{\sqrt{2 \pi} \sigma_{\varepsilon} R_{L}} \cdot e^{-\frac{\Delta z^{2}}{2\left(\sigma_{\varepsilon} R_{L}\right)^{2}}} d \Delta Z$

(9)

\section{The Probability Model of Penetration Target Detection}

Basic assumptions: first, the penetration of the aircraft into the effective range of airborne weapons after the start of the airborne radar; penetration of the aircraft once the enemy air defense missile system radar discovery is destroyed. Based on the above hypotheses, in considering the relationship between the position of the minimum distance of airborne weapon launch Rmin, the penetration aircraft target jamming exposure area radius D0 and the ground to air radar jamming target in the exposed area $D_{t}\left(\varphi_{\max }\right)$ of the three radius (as shown in Table 1) under the condition that the target probability of Pf penetration under the condition of radar jamming aircraft.

Table 1 rmin,D0 and $D_{t}\left(\varphi_{\max }\right)$ three position relation

\begin{tabular}{|c|c|}
\hline Position relation & conclusion \\
\hline $\operatorname{rmin}>\operatorname{Dt}(\psi \max )>\operatorname{D} 0$ & \multirow{2}{*}{$\begin{array}{l}\text { Penetration aircraft into the minimum range of airborne } \\
\text { weapons can not find the target, } \mathrm{Pf}=0\end{array}$} \\
\hline $\operatorname{rmin}>\mathrm{D} 0>\operatorname{Dt}(\psi \max )$ & \\
\hline $\mathrm{D} 0>\operatorname{rmin}>\mathrm{Dt}(\psi \max )$ & \multirow{2}{*}{$\begin{array}{l}\text { Penetration of the aircraft was destroyed by enemy air } \\
\text { defense missile weap on systems, Pf }=0\end{array}$} \\
\hline $\mathrm{D} 0>\mathrm{Dt}(\psi \max )>\operatorname{rmin}$ & \\
\hline $\operatorname{Dt}(\psi \max )>\operatorname{rmin}>\mathrm{D} 0$ & \multirow{2}{*}{ The probability of finding the target is Pf } \\
\hline $\operatorname{Dt}(\psi \max )>\mathrm{D} 0>\operatorname{rmin}$ & \\
\hline
\end{tabular}

(1) Dt $(\psi \max )>\operatorname{rmin}>\mathrm{D} 0$. (1) If $\operatorname{Dt}(\psi \max )>\operatorname{Dt}(0) \geq \mathrm{rmin}>\mathrm{D} 0$, the penetration aircraft found the target beyond the minimum range of airborne weapons, and is not to destroy enemy air defense missile weapon system, the penetration aircraft target detection probability Pf see Eq.10.(2)If $\operatorname{Dt}(\psi \max )>\operatorname{rmin}>\operatorname{Dt}(0) \geq \operatorname{D} 0$ or $\operatorname{Dt}(\psi \max )>\operatorname{rmin}>\operatorname{D} 0 \geq \operatorname{Dt}(0)$, this point the probability of penetration aircraft found Pf see Eq.11.The azimuth angle of the exposed area radius $\omega$ is equal to rmin.

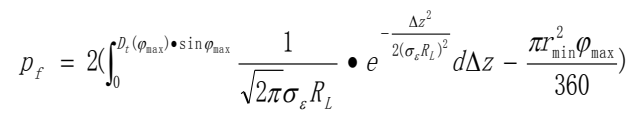

$p_{f}=2\left(\int_{0}^{D_{t}\left(\varphi_{\max }\right) \cdot \sin \varphi_{\max }} \frac{1}{\sqrt{2 \pi} \sigma_{\varepsilon} R_{L}} \cdot e^{-\frac{\Delta z^{2}}{2\left(\sigma_{\varepsilon} R_{L}\right)^{2}}} d \Delta z-\frac{\pi r_{\min }^{2}\left(\varphi_{\max }-\omega\right)}{360}\right)$

(2) $\operatorname{Dt}(\psi \max )>\mathrm{D} 0>\operatorname{rmin}$. (1) If $\operatorname{Dt}(\psi \max )>\operatorname{Dt}(0) \geq \mathrm{D} 0>$ rmin, penetration aircraft found target probability Pf see Eq.12(2)If $\operatorname{Dt}(\psi \max )>\operatorname{D} 0>\operatorname{Dt}(0)>\operatorname{rmin}$ or $\operatorname{Dt}(\psi \max )>\operatorname{D} 0>\operatorname{rmin}>\operatorname{Dt}(0)$, penetration aircraft found target probability Pf see Eq.13.The azimuth angle of the exposed area radius $\omega$ is 
equal to rmin.

$$
\begin{gathered}
p_{f}=2\left(\int_{0}^{D_{t}\left(\varphi_{\max }\right) \cdot \sin \varphi_{\max }} \frac{1}{\sqrt{2 \pi} \sigma_{\varepsilon} R_{L}} \cdot e^{-\frac{\Delta z^{2}}{2\left(\sigma_{\varepsilon} R_{L}\right)^{2}}} d \Delta z-\frac{\pi D_{0}^{2} \varphi_{\max }}{360}\right) \\
p_{f}=2\left(\int_{0}^{D_{t}\left(\varphi_{\max }\right) \cdot \sin \varphi_{\max }} \frac{1}{\sqrt{2 \pi} \sigma_{\varepsilon} R_{L}} \cdot e^{-\frac{\Delta z^{2}}{2\left(\sigma_{\varepsilon} R_{L}\right)^{2}}} d \Delta z-\frac{\pi D_{0}^{2}\left(\varphi_{\max }-\omega_{1}\right)}{360}\right)
\end{gathered}
$$

\section{Simulation Analysis}

$\mathrm{D} 0$ and $\mathrm{D}_{t}\left(\varphi_{\max }\right)$ were mainly controlled by the penetration aircraft jamming equipment jamming power density $\mathrm{Sz}$ and the effects of enemy air radar jamming equipment jamming power density Sd, the penetration aircraft airborne radar at the level of the maximum search angle of $\varphi_{\max }$, so the simulation analysis of major research Sz, Sd and $\varphi_{\max }$ on the effect that target probability Pf, simulation analysis of the parameters used in the process as shown in table 2.

\begin{tabular}{|c|c|c|}
\hline parameter & Parameter value & Explain \\
\hline$\frac{P_{t} G_{t}}{\Delta f_{r}}$ & $\begin{array}{l}1.5 \times 105 \\
\mathrm{~W} / \mathrm{MHz}\end{array}$ & Penetration of airborne radar power density \\
\hline$\frac{P^{\prime}{ }_{t} G_{t}{ }_{t}}{\Delta f^{\prime}{ }_{r}}$ & $8 \times 104 \mathrm{~W} / \mathrm{MHz}$ & $\begin{array}{l}\text { Power density of guidance radar for air defense missile } \\
\text { weapon system }\end{array}$ \\
\hline $\mathrm{H}$ & $1.5 \mathrm{~km}$ & Penetration flight altitude \\
\hline $\mathrm{RL}$ & $250 \mathrm{~km}$ & $\begin{array}{l}\text { The distance between the starting point of the bombing of the } \\
\text { aircraft and the ground navigation station }\end{array}$ \\
\hline$\sigma_{\varepsilon}$ & $0.02 \mathrm{rad}$ & \\
\hline$\sigma_{0}$ & $100 \mathrm{~m} 2$ & Effective reflection area of ground target \\
\hline$\sigma_{0}$ & $5 \mathrm{~m} 2$ & Effective reflection area \\
\hline $\mathrm{d}$ & $0.5 \mathrm{~km}$ & $\begin{array}{l}\text { The distance of ground to air radar jamming equipment from } \\
\text { the ground target center }\end{array}$ \\
\hline $\mathrm{L}$ & $20 \mathrm{~m}$ & Equivalent radius of ground target \\
\hline $\mathrm{Kj}$ & 4 & Airborne radar suppression factor \\
\hline$\gamma_{j}$ & 0.5 & Polarization loss of jamming signal to radar antenna \\
\hline rmin & $2 \mathrm{~km}$ & Minimum firing range of airborne weapon \\
\hline
\end{tabular}

Table 2 parameters used in the simulation

The integrated use of Eq. 9 to Eq. 12, the PSI Max is 30 degrees and 60 degrees and 90 degrees, $\mathrm{Sz}, \mathrm{Sd}$ and Pf, the simulation results shown in fig. 4 fig. 5 and fig. 6. 


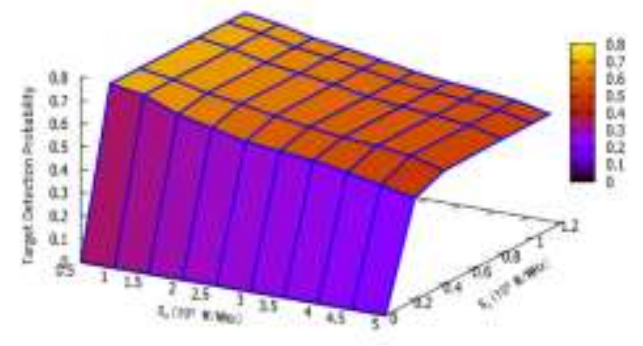

Figure 4. Finite $\psi \max =30^{\circ}$, the relationship of $\mathrm{Sz}, \mathrm{Sd}$ and $\mathrm{Pf}$

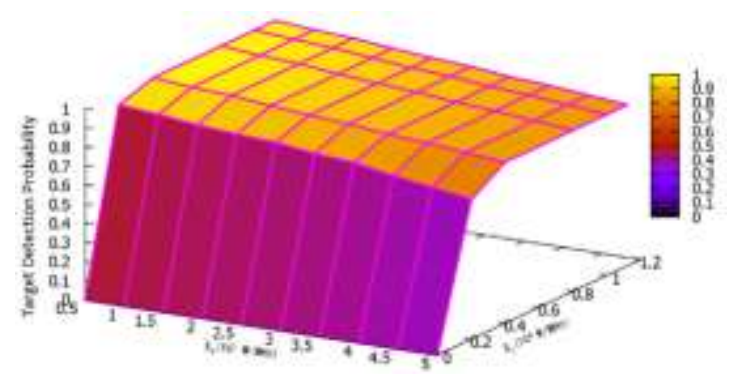

Figure 5. Finite $\psi \max =60^{\circ}$, the relationship of $\mathrm{Sz}, \mathrm{Sd}$ and $\mathrm{Pf}$

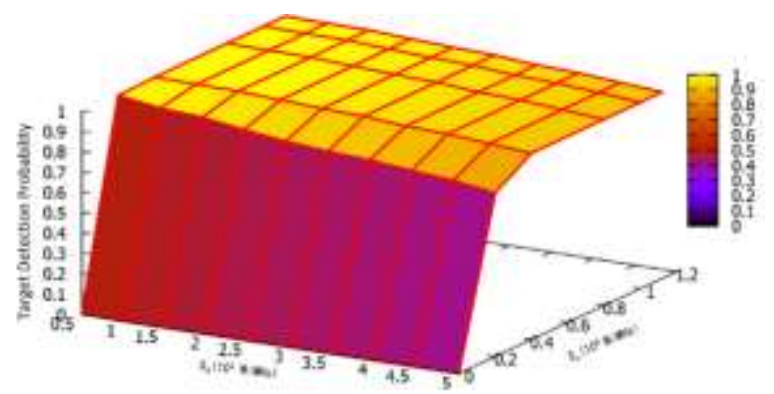

Figure 6. Finite $\psi \max =90^{\circ}$, the relationship of $\mathrm{Sz}, \mathrm{Sd}$ and $\mathrm{Pf}$

The simulation results show that: when $\mathrm{Sz}_{\mathrm{z}}=0$, the air defense missile weapon system guidance radar without interference, $\mathrm{D} 0=16 \mathrm{~km}$, at $\mathrm{Sd}$ value space, D0 is greater than $\mathrm{Dt}$ (or max), the aircraft penetration probability of target detection in $\mathrm{Pf}=0$; When the $0<\mathrm{Sz}$ is less than $0.4 * 105 \mathrm{~W} / \mathrm{MHz}$, $2.02 \mathrm{~km}=\mathrm{D} 0<16 \mathrm{~km}$. The $\mathrm{rmin}<\mathrm{D} 0<\mathrm{Dt}$ (or max), found that the influence of the penetration aircraft target probability $\mathrm{Pf}$ is mainly controlled by $\mathrm{Sd}$ and $\mathrm{Sz}$, with the increase of Sz, D0 decreased, Pf increased gradually, and with the increase of Sd, Dt (or max) decreased gradually, fall into the penetration aircraft airborne radar effective detection area to reduce the probability of ground targets Pf decreased; When the $0.4 * 105 \mathrm{~W} / \mathrm{MHz}<\mathrm{Sz} 1.2 * 105 \mathrm{~W} / \mathrm{MHz}, 0$ at $\mathrm{D} 0<=\mathrm{D} 0<2.02 \mathrm{~km}$, $\mathrm{Rmin}<\mathrm{Dt}$ (or max), found that the influence of the penetration aircraft target probability Pf is mainly controlled by Sd and Rmin, with the increase of Sd, Dt (or max) gradually decreased, falling into the ground target penetration aircraft airborne radar effectively detecting probability measure the area decreased, Pf decreased gradually.

\section{Conclusion}

Based on the analysis of the influence of the enemy threat factors and the factors that restrict the penetration of the aircraft to the ground attack stage, this paper establishes the probability model. On this basis, through the simulation analysis to verify the main factors influencing the model, 
obtained when only considering the incoming aircraft penetration in horizontal direction, the enemy ground to air radar jamming equipment jamming power density and airborne jamming equipment, airborne radar jamming power density factors in the horizontal plane angle of maximum search, found that the influence of curve of target probability, provides a new way for evaluating the penetration aircraft penetration effectiveness, but the two sides of the combat entity number is single, and the first deployment, the next step will focus on the research of the combat entity number is more than 1 and any deployment, discovery target probability model and calculation method of aircraft penetration.

\section{References}

[1] X.B. Cui. Theory and method of quantitative analysis of aviation tactics. Beijing: Blue Sky Press, 2009.

[2] Y.L. Zhang, L.Q. Jiang. Modeling of surveillance effectiveness of surface to air missile radar based on suppression jamming [J]. fire and command control, 2015,40(5):104-107.

[3] L.Zhang, B. Xiong. The noise of the search radar jamming effectiveness evaluation of Sichuan [J]. Acta ARMAMENTARII, 2014,14(6):113-115.

[4] X.Yang, Z.M. Wei. First attack probability model [J]. fire control and command control, 2004,29(3):24-26.

[5] J.L.Ai,G.H. Qian. The combat effectiveness analysis model for the attack stage of ground attack [J]. fire and command control, 2000, 25(2):15-18.

[6] J.Huang, Z.Wu. Effectiveness evaluation of air to ground attack on attacking aircraft [J].Aeronautical Journal,1999, 20(1):69-71.

[7] G.Y. Zhang, X.W. Liu. Evaluation model of air attack effectiveness of attacking aircraft under ground to air interference [J].Optoelectronics and control, 2011,18(5):9-10.

[8] G.Y. Zhang, X.W. Liu, etc. Study on the probability of attack aircraft entering target under electronic jamming $[\mathrm{J}]$.

Journal of missile and guidance,2011, 31(5):202-205.

[9] G.P. Shao. Analysis of electronic warfare operational effectiveness [M]. Beijing: Chinese people's Liberation Army press, 1998

[10] G.P. Chen, Y. Deng. Principles of aeronautical radio navigation [M]. Beijing: National Defence Industry Press, 2008 